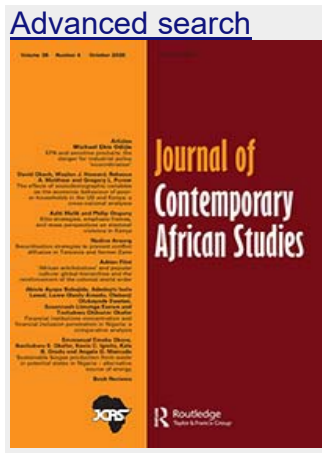

Journal of Contemporary African Studies Volume 38, 2020 - Issue 4 Submit an article Journal homepage

\title{
Sustainable biogas production from waste in potential states in Nigeria - alternative source of energy
}

Emmanuel Emeka Okoro (iD, Ikechukwu S. Okafor, Kevin C. Igwilo, Kale B. Orodu \& $\underline{\text { Angela }}$ O. Mamudu iD

Pages 627-643 | Received 10 May 2018, Accepted 15 Sep 2020, Published online: 02 Nov 2020

- $\quad$ Download citation

- $\quad$ https://doi.org/10.1080/02589001.2020.1825650

- Full Article

- $\quad$ Figures \& data

- _References

- $\quad$ Citations

- $\quad$ Metrics 
Most states in Nigeria are faced with the challenge of ensuring a sustainable energy supply and safe waste management. Anaerobic digestion meets the requirements of sustainable alternative fuels and is also an environmental disposal method. Producing clean alternative biogas energy from waste is also one of the best ways to meet these challenges. This study uses a bottom-up resource-oriented approach to assess the biogas potential in Nigeria through the use of organic waste. The objective is to analyse the potential in utilising the available organic waste during anaerobic digestion. The analysis summarises several studies on this issue from 2001 to 2019, and their conclusions are highlighted and used to infer the importance of converting these organic wastes into biogas. The environmental impact of the process is so great that it must be taken into account. However, Nigeria does not have an appropriate and suitable source separation scheme and should invest in waste separation. Source separation or central separation, as the environmental impacts associated with waste management and biogas production, must be considered. The results show the considerable potential of biogas over the next three decades due to rising waste generation and proposed deployment of infrastructure for improving waste collection efficiency.

\section{KEYWORDS:}

Biogassustainable and renewable energypost-harvest wastealternative source of energyorganic fraction

\section{Log in via your institution}

\section{Loading institutional login options...}

\section{Log in to Taylor \& Francis Online}

Log in

Restore content access

Restore content access for purchases made as quest

\section{Purchase options * Save for later}

\section{USD 45.00Add to cart}

Issue Purchase

- 30 days online access to complete issue

- Article PDFs can be downloaded

- Article PDFs can be printed

USD 559.00Add to cart

* Local tax will be added as applicable 


\section{Acknowledgement}

The authors wish to appreciate the Management of Covenant University for their financial support.

\section{Disclosure statement}

No potential conflict of interest was reported by the authors. 